\title{
Berteologi Menurut Paul Ricoeur: Sebuah Sumbangan Metodologis
}

\author{
John C. Simon
}

\begin{abstract}
Abstrak:
"He who is unable to reinterpret his past may also be incapable of projecting concretely his interest in emancipation" (Paul Ricoeur). In understanding a theologizing process, our attention should not focus on reality alone, but also on the means or tools to understand that reality. This paper intends to explain the means or tools of the theologizing process according to Ricoeur that is used to understand a reality. As a process, it shall not be only about method, but also methodology, namely a process of thinking, the brought interest and the achieved value premises. Its guiding question is Ricoeur's theologizing methodology called hermeneutics. Through dialogue with many partners, Ricoeur found a methodology of realityreading, first affirmative then critical. This is an affirmative-critical gesture. However, this methodology is inadequate to do reading on an extreme context. It takes effort to reverse Ricoeur's methodology by first prioritizing the critical against the reality distortion, and only then be affirmative to uncover hope of a good and just life. Finally, the theologizing process requires a dialectical methodology of reading a reality, between critical-affirmative and affirmative-critical gestures. Context at hand shall determine what goes first.
\end{abstract}

Kata-kata Kunci:

metodologi, hermeneutik, emansipatoris, mitra dialog, dialektis, kritis-afirmatif, afirmatif-kritis.

\section{PENDAHULUAN}

Dalam mengerti proses berteologi, per mitra dialog hatian kita tidak hanya tertuju pada realitas, melainkan juga pada sarana atau alat untuk memahami realitas. Hanya saja, sebaik apapun sarana atau alat yang dipakai, ia tidak dapat menggantikan realitas. Realitas jauh lebih besar dari semua sarana atau alat untuk memahaminya. Realitas pun tidak dapat dibatasi dalam kerangka tertentu yang ada pada sarana atau alat untuk memahaminya.

Sekalipun demikian, sarana atau alat tetap penting dalam upaya memahami realitas yang demikian kaya, elusif dan tidak pernah akan menjadi fix meaning. ${ }^{\text {B Ber- }}$ hadapan dengan realitas, keyakinan yang tumbuh bersifat "terbatas" (contingent, temporer, kontekstual) ${ }^{2}$ menurut kemampuan kita menangkap dan sangat ditentukan oleh konteks waktu dan tempat tertentu, dan "bisa juga salah" (fallible). ${ }^{3}$ Kesadaran ini biasanya kita wujudkan dalam pengertian bahwa pemahaman universal tidak akan pernah tercapai, karena kita begitu terbatas. Sejalan itu, alam pikir postmodern mempromosikan cara pandang skeptis dan nihilis, khususnya terhadap klaim-klaim tentang potensi pemikiran dan tindakan manusia. ${ }^{4}$ Postmodern juga menolak optimisme era 
modern tentang kemajuan dan pembangunan, termasuk optimisme dapat mencapai pengetahuan universal yang merangkum semua hal.

Berangkat dari latar berpikir di atas, tulisan ini bermaksud menjelaskan alat atau sarana dalam proses berteologi menurut Paul Ricoeur untuk memahami realitas. Sebagai sebuah proses, maka yang mau disentuh tidak hanya soal metode, melainkan metodologi, yaitu proses berpikir, kepentingan yang diusung dan premis nilai yang dicapai. Tulisan ini bermaksud menjawab pertanyaan, apa metodologi berteologi yang ada dalam pemikiran Ricoeur? Basis berpikir Ricoeur sering disebut dengan hermeneutik. Secara umum hermeneutik dipahami sebagai "seni memahami". ${ }^{5}$ Di dalam seni memahami terkandung apa yang Ricoeur sebut "nilai paradigmatik" (paradigmatic value). 6 Yang termasuk ke dalam seni memahami adalah memahami realitas di mana manusia hidup dengan posisi mana keprihatinan konteks itu ditanggapi. Dalam tulisan ini akan diperlihatkan bagaimana Ricoeur berdialog dengan Gadamer dan Habermas yang masingmasing menyumbang posisi atau gestur teologis tertentu dalam pemikiran Ricoeur. Lalu, di akhir bahasan akan diperlihatkan upaya metodologis dialektis sebagai upaya merelevansikan pemikiran Ricoeur.

\section{MITRA DIALOG PAUL RICOEUR}

Hermeneutik Paul Ricoeur sering disebut sebagai hermeneutik emansipatoris, yaitu hermeneutik yang bertujuan etis untuk pembebasan. Ricoeur menyinggung tugas emansipasi ketika mengatakan, "hermeneutics without a project of liberation is blind, but a project of emancipation without historical experience is empty". ${ }^{7}$ Yang berbeda dari hermeneutik lainnya bahwa titik tolak Ricoeur dalam memahami adalah dimulai dari diri sendiri, karena itu hermeneutiknya disebut "hermeneutik tentang diri" (hermeneutics of the self) ${ }^{8}$ Diri dahulu dipahami dan diemansipasi untuk bebas dari kecenderungannya yang tertutup dan hanya mementingkan diri sendiri, menuju diri yang terbuka dan terlibat dalam keprihatinan konteks. Diri yang terbuka itu adalah diri yang hidup baik bersama yang lain dalam institusi-institusi yang adil.

Dalam mengonstruksi pembebasan atas diri, hermeneutik emansipatoris membangun kapasitasnya dalam dialog dengan pemikiran-pemikiran kritis lainnya. Dalam dialognya, Ricoeur menjelajahi (detour) berbagai macam tanda, simbol, metafora, dan narasi yang tersaji melalui pemikiranpemikiran tersebut, dan kemudian kembali (returning) kepada hermeneutik tentang diri (hermeneutics of the self). Kata Ricoeur "I understand myself only by means of the signs that I give of my own life and that are returned to me via others. All self-knowledge is mediated through signs and works". ${ }^{9}$ Tujuan dari upaya penjelajahan itu adalah tercapainya emansipasi subjek untuk mempunyai tampilan yang berbeda dan menata secara baru kehadiran dan tindakannya. Kata Ricoeur, "that the interpretation of a text culminates in the self-interpretation of a subject who thenceforth understands himself better, understands himself differently, or simply begins to understand himself". ${ }^{10}$

Mitra dialog Ricoeur untuk proyek emansipasi subjek dapat dikelompokkan menjadi tiga bagian. Pertama, Ricoeur menerima masukan dari tokoh-tokoh sekolah kecurigaan (school of suspicion), yaitu Marx, Nietzsche dan Freud, untuk melangkah pada "transformasi subjektivitas" dengan tujuan meruntuhkan ilusi subjek yang absolut, yang eksploitatif dan dominatif. Kedua, Ricoeur pun bermitra dengan Gadamer dan Habermas untuk mempertemukan dua gestur hermeneutik. Yang satu afirmatif dari tradisi romantisme, sementara yang lain kritis dari tradisi pencerahan. Dalam rangka hermeneutiknya, Ricoeur memanfaatkan kedua gestur hermeneutik tersebut untuk menegaskan apa yang bahasa Alkitab sebut pembebasan, tentang sebuah eksodus (exodus) dan kebangkitan (resurrection). Menurut Ricoeur, kepentingan emansipasi tidak lagi menarik, juga tidak mengandung harapan akan kebebasan, kalau tradisi tentang eksodus dan kebangkitan yang dulu berlaku dihapus dari ingatan umat manusia. Ketiga, Ricoeur berdialog dengan Levinas. Ia menerima kritik atas ontologi klasik yang dilakukan oleh Levinas. 
Namun, Ricoeur mengkritik etika asimetris Levinas seraya menjadikan pemikiran Levinas sebagai pintu masuk pada pemahaman diri yang terbuka ke arah emansipasi diri di dalam institusi-institusi yang adil. Lewat usulannya tentang sebuah etika simetris yang saling memberi dan menerima dalam kesetaraan, Ricoeur mempertimbangkan adanya institusi dan sistem demokrasi sebagai konsensus publik di dalam rangka hidup bersama secara adil.

Motif utama sekaligus irama pernafasan dari seluruh bangunan filsafat Ricoeur adalah detour/return. ${ }^{1 l}$ Detour/return merupakan kekuatan dari metode hermeneutik Ricoeur, kata Blundell. ${ }^{12}$ Namun, menurut saya, detour/return sekaligus merupakan metodologi atau nilai paradigmatik, yaitu kepentingan hermeneutik dan posisi teologis Ricoeur dalam merefleksikan kesadaran subjek yang tidak tertutup (seperti yang disangkakan Descartes, Kant, Husserl), melainkan terbuka keluar (afirmasi) dan berada bersama yang lain dalam tindakan etis dan adil. Sebagai sebuah paradigma, maka "this long detour is, precisely, suspicion". ${ }^{13}$ Sebagai jalan kecurigaan maka tugas emansipasi tidak pernah ditempuh langsung (immediate) atau melalui "jalan pendek" (short route), melainkan ditempuh melalui "jalan panjang" (long detour, long route), yaitu melewati aneka perjumpaan, dialog dan momen "kecurigaan" (suspicion) sampai ilusi subjek yang pongah dan merasa cukup dengan dirinya diruntuhkan. Di sinilah momen emansipatoris Ricoeur mengusung kepentingan sebagai pembebasan atau emansipasi atas subjek untuk terbuka dalam hidup bersama yang lain di dalam institusi-institusi publik yang adil.

Ketiga guru kecurigaan (Marx, Nietzsche dan Freud), Habermas dan Gadamer serta Levinas, masing-masing menyumbang apa yang disebut Ricoeur "transformasi subjektivitas" yang disebut juga emansipasi subjek. Transformasi diri itu membuat subjek mencapai second naïvete,${ }^{14}$ yaitu subjek yang baru, yang dilahirkan dengan meruntuhkan ilusi subjek yang serba tahu dan pongah yang tampil dalam tindakan eksploitatif dan dominatif. Melalui kritik atas ilusi subjek tergambar jelas apa yang Ricoeur sendiri sebut tentang pemikirannya sebagai "filsafat antropologi" yang isinya mengenai gambaran dunia baru dengan visi tentang manusia yang lebih baik dan adil. ${ }^{15}$ Melalui ketiga guru kecurigaan (Marx, Nietzsche dan Freud), Habermas, Gadamer dan Levinas, tersusun pula tugas hermeneutik kritis emansipatoris, yaitu menguak kepentingan yang melandasi semua usaha pengetahuan entah basisnya pada ekonomi (Marx), psikologi (Freud), antropologi (Nietzsche), hermeneutik (Gadamer), kritik ideologi (Habermas) dan etika (Levinas) - bagi terbitnya emansipasi ruang privat dan ruang publik. Kesemua mitra dialog Ricoeur menyuguhkan sarana atau alat bagi hermeneutik emansipatoris yang sejalan dengan fungsi teori sosial kritis di mana "task for a critical social theory is to argue for a conception of justice that challenges institutionalized domination and oppression while affirming a heterogeneous public and group differences". ${ }^{16}$ Lantas terciptalah cara baru melihat diri dan dunia yang tidak lain merupakan cara baru berada di dalam dunia (being-in-the-world) yang adil dan manusiawi.

Dalam memahami realitas, Paul Ricoeur menerangkan bahwa hermeneutik dipahami sebagai refleksi yang dimediasi. Hermeneutik menjelaskan bahwa tidak ada pemahaman diri tanpa diperantarai oleh tanda, simbol, teks termasuk kehadiran orang lain. Pemahaman diri tidak akan terjadi kecuali melalui jalan panjang (long detour) termasuk melalui kehadiran orang lain yang berbeda dengan kita. Kata Ricoeur, "I give of my own life and that are returned to me via others". ${ }^{17}$ Pemahaman diri atau disebut juga refleksi dipahami sebagai ajakan kembali ke diri sendiri. Secara teologis, Ricoeur merefleksikan hal ini sebagai, "what the Gospel says of the soul: to be saved, it must be lost [...] the self (le moi) must be lost in order to find the 'I' (le je)"..$^{18}$ Lahirlah diri yang baru (second nä̈vete), ${ }^{19}$ yakni diri dalam tanggung jawab moral bersama dan dengan yang lain di dalam institusi yang adil. Ricoeur juga hendak memperlihatkan betapa pentingnya phronesis, yaitu kebijaksanaan praktis dalam kehidupan konkret, yang melaluinya kita dapat mencapai pemahaman diri kita melalui yang lain (oneself as another) berkat segala kemampuan diri yang selalu dime- 
ngerti sebagai diri yang terbuka dan terbagi untuk yang lain.

\section{SUMBANGAN GADAMER DAN HABERMAS DALAM PEMIKIRAN RICOEUR}

Seperti disebut di atas, salah satu mitra dialog Ricoeur adalah Gadamer dan Habermas. Hans-Georg Gadamer (1900-2002) mewakili tradisi hermeneutik, sedangkan Jürgen Habermas (1929-) mewakili teori kritis atau kritik ideologi. Ricoeur mempertimbangkan sumbangan Gadamer dan Habermas dalam pemikirannya dengan mengatakan pernyataan penting bahwa hermeneutik dan kritik ideologi bisa saling menopang. ${ }^{20}$

Secara deskriptif, terdapat empat perbedaan antara hermeneutik dan kritik ideologi. ${ }^{21}$ Pertama, hermeneutik Gadamer berusaha merehabilitasi prasangka, tradisi dan otoritas dengan mengaitkannya dengan pemahaman Heidegger tentang "proyek keterlemparan" (thrown project) di mana Dasein hanya menerima tanpa pernah bisa mengkritik, sementara itu kritik ideologi Habermas mengembangkan konsep kepentingan yang berasal dari tradisi Marxis atau pencerahan yang gesturnya pembebasan. Kedua, hermeneutik Gadamer menggunakan ilmu-ilmu kemanusiaan untuk menginterpretasi kembali dan mengatasi penjarakan dari tradisi, sementara itu kritik ideologi Habermas menggunakan ilmu-ilmu sosial kritis dengan tujuan untuk membuka kemungkinan-kemungkinan emansipasi melalui refleksi kritis atas bahaya reifikasi (pembendaan) dan alienasi ideologis. ${ }^{22}$ Ketiga, hermeneutik Gadamer menerima kesalahpahaman sebagai rintangan menuju pemahaman, sementara itu bagi Habermas setiap rintangan adalah ideologi atau komunikasi yang didistorsi secara sistematik yang memunculkan konsensus palsu dan pseudo-komunikasi. Keempat, Gadamer mendasarkan tugas hermeneutik pada ontologi bahasa sebagai kesadaran sejarah yang given, sementara itu Habermas justru mengaitkan teori komunikatif dengan prinsip komunikasi tak-terbelenggu.

Secara sederhana perbedaan keduanya adalah antara hermeneutik yang cenderung rendah hati dan kritik ideologi yang garang menentang semua hal yang menyembunyikan kepentingan dan kesadaran palsu. Menurut Kaplan, perbedaan itu adalah "the humility of philosophical hermeneutics and the defiance of the critique of ideology". 23 Hermeneutik menekankan keterbatasan dan kondisi-kondisi historis di mana kita menjadi bagiannya, sementara kritik ideologi menentang distorsi-distorsi tersembunyi dan sistematik dari pemahaman diri tentang komunitas ideal dalam komunikasi tak terbelenggu.

Dari perbedaan yang ada, maka pertanyaan yang muncul adalah: Apakah bisa membuat hermeneutik yang dapat melakukan kritik? Atau, dengan kata lain: Bisakah kritik lahir dalam hermeneutik? ${ }^{24}$ Ricoeur menawarkan empat suplemen bagi hermeneutik yang dapat menjalankan fungsi kritik ideologi. ${ }^{25}$ Pertama, pengakuan adanya jarak (distance) sebagai momen penting untuk membuka kemungkinan bagi kritik di dalam hermeneutik. Kita tidak pernah menjadi bagian dari tradisi atau cakrawala yang dihidupi selama kita tidak dapat merefleksikan batas-batas pemahaman kita sendiri. Kedua, mengatasi dikotomi antara penjelasan (explanation) dan pemahaman (understanding) untuk menyatukan keduanya secara dialektis dengan tujuan menghitung kemampuan melakukan kritik, utamanya kritik terhadap ilusi subjek yang absolut model cogito Descartes dan solipsistis Husserl. ${ }^{26}$ Ketiga, pengakuan pada dimensi referensial (mediasi) sebagai kekuatan yang potensial bagi imajinasi tentang hidup yang lebih baik di dalam institusiinstitusi yang adil. ${ }^{27}$ Bagi Ricoeur, perluasan teori interpretasi ke wilayah tindakan manusia menjadi mungkin karena tindakan itu sendiri merupakan rujukan dari berbagai teks. Dengan meminjam mimesis-nya Aristoteles, Ricoeur mengatakan bahwa tindakan manusia adalah kreativitas tiruan (creative imitation) manusia. ${ }^{28}$ Dalam setiap imajinasi kreatif terdapat mimesis untuk meniru tentang sebuah tindakan untuk hidup yang lebih baik. Keempat, terdapat hubungan antara transformasi subjektivitas dan kritik atas kesadaran palsu. Di sini setiap interpretasi mensyaratkan interpretasi diri. Dalam proses mengin- 
terpretasi itu, maka "saya tidak lagi menyadari diri saya" (I unrealise myself). Interpretasi memperkenalkan kepada saya "ragam ego imajinatif". ${ }^{29}$ Ragam ego imajinatif inilah, menurut Ricoeur, yang membuka kemungkinan bagi "kritik atas ilusi subjek", sebab aku bukanlah keberadaan yang sendiri dan tertutup (solipsistis) melainkan berada dengan yang lain dan terbuka melalui relasi-relasi yang makin meluas. Bahkan melalui dialog terbuka, ilusi subjek yang tertutup diperhadapkan pada kritik terus-menerus hingga akhirnya diruntuhkan. Di sinilah yang lain diterima dengan sikap keramahan dan ikut menentukan keberadaan diriku. Yang lain adalah pembentuk identitasku. Konsep inilah yang tidak berkembang di dalam hermeneutik tradisi karena terlalu cepat memperkenalkan "pendakuan" (Aneignung, appropriation) yang tujuannya untuk menampik penjarakan yang dianggap mengasingkan. Ketika penjarakan ditampik, maka kritik pun tidak muncul dan subjek absolut tetap menjadi masalah. Karena itulah, kritik ideologi harus ditempatkan sebagai sejawat dari kritik atas ilusi subjek. Begitu pula kritik atas kesadaran palsu bukan pasangan yang terpisah dari hermeneutik. Dengan demikian, refleksi diri membuka pada refleksi kritis yang penting bagi emansipasi subjek. Sehingga setiap interpretasi atas ilusi subjek dengan cara yang sama merupakan kritik ideologi. Tujuannya adalah melahirkan seorang individu yang terbuka menerima kehadiran yang lain dan terbuka pula berdialog dalam kesetaraan untuk membangun kehidupan yang lebih baik dan adil.

Perdebatan antara Gadamer dan Habermas juga berpusat pada apa makna dan fungsi tradisi. ${ }^{30}$ Jika Gadamer memandang tradisi sebagai sumber kesadaran historis untuk mencapai pemahaman, Habermas memandang tradisi sebagai sumber distorsidistorsi sistematik yang melanggengkan dominasi. Kaplan menggambarkan persoalannya demikian:

"Habermas claims that Gadamer rightly ties understanding to historical understanding conciousness but offers no possibility of transcendence in order to evaluate our historically effected consciousness. If there is no transcendental perspective on history, then there is no way to recognize if my tradition is ideologically distorted. If there is no way to recognize ideological distortions, then there is no way to criticize the domination and injustice tradition may conceal". ${ }^{31}$

Dari analisis itu, Gadamer sesungguhnya menyetujui Habermas bahwa bahasa bukan hanya tempat rasionalitas dan konsensus tetapi juga tempat pemaksaan dan dominasi. Jika begitu, maka "Hermeneutics is already a critique of conciousness and communication". ${ }^{32}$ Secara dialektis Ricoeur sudah mengungkap kedua fungsi itu dalam satu kesatuan: "The gestur of hermeneutics is a humble one of acknowledging the historical conditions to which all human understanding is subsumed in the reign of finitude; that of the critique of ideology is a proud gesture of defiance directed against the distortions of human communication".33 Dengan dua gestur hermeneutik yang satu rendah hati dan yang lain kritis, tujuannya adalah sama-sama menentang "kesadaran palsu", yaitu distorsi komunikasi manusia yang menyembunyikan dominasi dan kekerasan. Bagi Ricoeur, hermeneutik dan kritik ideologi adalah pasangan dan bisa saling menopang untuk mengemansipasi wilayah privat, yaitu meruntuhkan subjek absolut, dan wilayah publik, yaitu dari pembudayaan dominasi dan kekerasan.

Menurut Ricoeur perdebatan antara Gadamer dan Habermas merupakan dua sikap fundamental filsafat, yaitu (1) ketundukan pada keterbatasan (afirmatif), dan (2) perlawanan terhadap dominasi (kritiskonfrontatif). ${ }^{34}$ Ricoeur menerima keduanya, baik rehabilitasi tradisi dan pemahaman historis dalam kasus hermeneutik tradisi Gadamer, dan kecurigaan terhadap penyimpangan institusi melalui bahasa dan kekuasaan dalam kasus kritik ideologi Habermas.

Selain itu, gagasan Gadamer tentang prasangka juga penting. ${ }^{35}$ Sebab, prasangka yang sudah mendarah daging akan sulit dikritik dan justru akan menjadi ideologi. Atas hal ini Ricoeur lalu membuat "jalan tengah" antara penerimaan akan tradisi (Gadamer) dan kecurigaan (Habermas) atasnya. Jalan tengah ini dibangun oleh jalan pe-nalar-an. Kata Ricoeur: "makes its plea 
before the tribunal of reason". ${ }^{36}$ Dalam nalar yang demikian, kita seharusnya menerima klaim kebenaran tradisi atau otoritas sebagai benar menurut anggapan tertentu sampai ada argumen lebih baik yang menunjukkan sebaliknya dan kita pun bersedia mengubah pandangan yang terbukti keliru tersebut. Dalam pengalaman hermeneutik, momen keterbukaan dan penerimaan mendahului momen kritik dan penjelasan. Kata Ricoeur:

\begin{abstract}
"that confident reception by which we respond, in an initial move preceding all criticism, to any proposition of meaning, any claim to truth, because we are never at the beginning of the process of truth and because we belong, before any critical gesture, to a domain of presumed truth". ${ }^{37}$
\end{abstract}

Dengan jalan pe-nalar-an tersebut, maka sahnya sebuah otoritas tradisi bahkan ideologi hanya terjadi dalam proses komunikasi dan argumentasi dikursif di antara interlokusioner yang saling berdialog. ${ }^{38}$ Dalam dialog tidak ada argumen yang bebas dari kritik. Semua argumen, termasuk agama yang dianggap sakral sekalipun, terbuka pada proses diskusi dan kritik. Di luar itu hanyalah komunikasi yang dipaksakan dan penuh dominasi. Dari sini pun menjadi jelas bahwa posisi Ricoeur dalam menjembatani antara apa yang sekarang terjadi (misalnya: kondisi ketidakadilan) dan apa yang seharusnya (keadilan) adalah model kebenaran yang diasumsikan tunduk pada keabsahan rasional. Sehingga hermeneutiknya pun tergolong hermeneutik kesadaran (hermeneutic consciousness). ${ }^{39}$ Namun, berbeda dengan kesadaran yang berpusat pada subjek absolut yang dalam filsafat Barat bersifat egologis, maka kesadaran yang Ricoeur maksud adalah "kesadaran tentang hidup secara baik" (consciousness of life as well) bersama yang lain dalam tindakan yang adil. $^{40}$ Dari sini pula menjadi jelas tugas refleksi filsafat yang dimaksud Ricoeur, "in the reinterpretation of cultural heritages received from the past and the interest in the futuristic projections of a liberated humanity". ${ }^{41}$

Ricoeur sepakat dengan Habermas dan Gadamer bahwa setiap kritik atas tradisi dan otoritas dimediasi oleh cita-cita regulatif akan komunikasi yang tak terbatas dan bebas dominasi (Habermas), yang, pada gilirannya, sikap kritis tetap ditempatkan secara historis dengan maksud agar dapat diterapkan dalam konteks tertentu (Gadamer). ${ }^{42} \mathrm{Di}$ sini kesadaran sejarah penting karena arah keprihatinan yang dikritisi itu tertuju kepada sejarah manusia konkret dan menuju emansipasi yang konkret pula. Seperti Habermas, Ricoeur lebih suka menekankan dasar keabsahan komunikasi agar kita mampu mencapai pemahaman yang benar dalam komunikasi. Tidak ada komunikasi yang dipaksakan, karena itu semua argumen layak untuk didengar. Tidak ada juga argumen yang bebas kritik. Dalam komunikasi, diandaikan sebuah kemampuan untuk menjelaskan diri sendiri dengan apa yang kita katakan sebaik mungkin. Ricoeur setuju dengan pendapat Habermas bahwa "The goal of coming to an understanding is to bring about an agreement that terminates in the intersubjective mutuality of reciprocal understanding, shared knowledge, mutual trust, and accord with one another". ${ }^{43}$ Yang paling penting bahwa Ricoeur menggemakan mediasinya perihal perdebatan Habermas dan Gadamer yang mengerucut pada kearifan praktis (practical wisdom), ${ }^{44}$ yang berisi keyakinan yang dihormati, argumen yang baik dan hasrat untuk hidup baik bersama dan demi orang lain dalam institusi-institusi yang adil.

Diskusi antara hermeneutik dan kritik ideologi sesungguhnya menghantar percakapan ini pada fungsi ideologi dalam hubungannya dengan membaca konteks atau realitas -termasuk itu tradisi dan otoritas. Menurut Ricoeur, fungsi ideologi adalah pertama-tama "to pattern, to consilidate, to provide order to the course of action". ${ }^{45}$ Fungsi primer ini juga disebut "the integrative function of ideology, the function of preserving an identity". Fungsi primer ini merupakan sumbangan Gadamer dalam pemikiran Ricoeur. Setelah fungsi primer ini kita mendapati fungsi kedua, yaitu "ideology as distortion and as the legitimation of a system of order or power". ${ }^{46}$ Fungsi sekunder ini merupakan sumbangan Habermas dalam pemikiran Ricoeur. Jelaslah bahwa bagi Ricoeur fungsi primer ideologi adalah integratif dan fungsi sekundernya adalah 
distortif. Jika kedua fungsi ini dipakai untuk membaca realitas, maka secara metodologis, Ricoeur memulai dengan sikap afirmatifintegratif baru kemudian kritis-konfrontatif terhadap distorsi atas realitas.

\section{MEMBALIK PRINSIP METODOLOGIS: DARI FUNGSI KRITIS KE FUNGSI INTEGRATIF}

Konstruksi Ricoeur tentang ideologi sangat positif karena sisi yang ditekankan adalah fungsi ideologi sebagai identitas dan integrasi sosial. Inilah fungsi primer ideologi, yang mendahului fungsi sekundernya yang bersifat kritis-konfrontatif terhadap semua distorsi, praktek kekerasan, ketidakadilan dan kesadaran palsu. Persoalannya bahwa posisi hermeneutik Ricoeur yang afirmatif ini sekaligus menjadi titik lemahnya dalam membaca konteks yang sudah sangat patologis akibat globalisasi imperialisme yang menyebabkan kemiskinan, kerusakan lingkungan dan ketidakadilan yang menaikkan tensi radikalisme dan terorisme. Ricoeur "terlalu percaya diri" (over-confident), bahkan terlalu berpikir positif terhadap realitas sehingga pemikirannya tidak relevan dengan realitas yang sebenarnya sudah demikian patologis dengan segala relasi-relasi kooptatif, dominatif dan tidak adil. ${ }^{47}$

Saya mengusulkan bahwa dalam rancang bangun metodologi berteologi kontekstual, maka menafsir kenyataan yang sudah distortif penuh praktek kekerasan dan ketidakadilan itu berarti memperlihatkan tugas hermeneutik yang bertolak dari tahapan kritis (hermeneutics of suspicion) menuju ke tahapan afirmasi (hermeneutics of affirmation). ${ }^{48}$ Dengan membalik jalan metodologis, maka kita bergerak dengan pisau kecurigaan (suspicion) terlebih dahulu untuk membuka selubung kepentingan (debunking) yang bermain di dalam relasi ideologi yang dominatif, menindas dan tidak adil, baru dari sana kita mengafirmasi dan mengintegrasikan sebuah mimpi dan pengharapan untuk hidup baik bersama orang lain. Secara teologis, Ricoeur adalah penggagas paradigma hermeneutik Kerajaan Allah dengan mengusung kepentingan keadilan sebagai premis nilai yang diperjuangkannya ${ }^{49}$ Tugas menghadirkan Keraja- an Allah ini pertama-tama adalah sebuah tugas hermeneutik yang kritis dan secara etis mengusahakan keadilan, perdamaian dan keutuhan ciptaan. Lebih lanjut, bagaimana fungsi kritis dan afirmatif ini bekerja?

Berbeda dengan Habermas yang mengatakan bahwa ideologi dominan saat ini adalah ilmu pengetahuan dan teknologi, ${ }^{50}$ maka menurut Ricoeur, ideologi dominatif saat ini adalah homo oeconomicus. ${ }^{51}$ Tampilan paling menyolok dari spirit homo oeconomicus adalah ekspansi, dominasi dan penindasan di bidang ekonomi. Sejalan dengan dominasi ekonomi, maka perlakuan terhadap ekologi juga tak kalah ganasnya diperas dan dieksploitasi melampaui batas regenerasinya. Sekarang imperialisme modern yang menyatukan kekuatan penghancur ekonomi dan ekologi pun digerakkan oleh roh yang sama demi untuk tetap survive sekalipun itu dilakukan dengan menebar teror dan peperangan di mana-mana.

Bertahannya spirit dominasi ini dapat pula dijelaskan lewat perspektif sejarah. Ricoeur sendiri memang memaksudkan emansipasi tidak terpisah dari kesadaran sejarah, yaitu sejarah penindasan dan ketidakadilan dari manusia-manusia yang kalah. Tentang sejarah Ricoeur berpendapat: "History would be economic history, history made by the homo oeconomicus - and not political history, history made by the man of prey". ${ }^{52}$ Dengan logika hidup yang saling memangsa untuk memperbesar keuntungan sendiri, maka tercipta apa yang Ricoeur sebut catastrophic situation, ${ }^{53}$ yaitu situasi ketimpangan antara yang menang dan yang kalah, hingga menciptakan kematian pada hidup bersama karena manusia memangsa manusia lainnya. Catastrophic situation juga berarti situasi di mana bahaya besar berupa ketidakadilan, kemiskinan dan kerusakan ekologi sudah menyatu menjadi daya kematian bagi kehidupan bersama.

Seperti jelas di atas, upaya kritis Ricoeur dengan mengambil jalan pe-nalaran, juga didasarkan pada kesadaran bahwa ideologi modern berupa homo oeconomicus telah bermain di wilayah proses rasionalisasi yang bermaksud menjinakkan wilayah tindakan instrumental dan memanipulasi praksis, yaitu "kehidupan yang baik" (good 
life). ${ }^{54}$ Praksis tertekan atau tergencet karena terpisah secara diametral dengan teori atau refleksi. Teori pun memanipulasi realitas atau praksis hidup konkret sehingga menciptakan tindakan-tindakan tuna-etik dan tuna-moral. Homo oeconomicus sebagai ideologi pun menjadi alat legitimasi kekuasaan yang kuat atas yang lemah sehingga praksis hidup yang baik dan adil tidak pernah muncul, tersembunyi oleh aneka kepentingan yang menindas.

Karena itu, konteks globalisasi imperialisme yang patologis membutuhkan metodologi (paradigma) menganalisis yang baru, yaitu dengan membalik prinsip afirmatifkritis menurut Ricoeur menjadi kritisintegratif. ${ }^{55}$ Dalam konteks globalisasi imperialisme yang demikian menggurita dengan praktik kekerasan dan dominasi yang kuat atas yang lemah, hermeneutik kritis emansipatoris pertama-tama akan melihat tantangan konteks tersebut sebagai persoalan ideologis, yaitu distorsi atas realitas (fungsi sekunder), karena persoalan ketidakadilan terjadi di mana-mana. Di sini fungsi kritis tidak tergantikan oleh fungsi integratif. Secara metodologis, kritik atas distorsi realitas ketidakadilan adalah langkah pertama yang dilakukan, baru kemudian mengafirmasi sebuah pengharapan tentang kehidupan yang lebih baik. Dari melihat akar persoalan sosial secara kritis itu kita bergerak menuju gagasan integratif-transformatif untuk mengubah realitas menjadi lebih baik dan lebih adil.

Mengedepankan cara membaca kritis atas realitas yang kental dengan dominasi, ketidakadilan dan distorsi (fungsi sekunder) justru menolong kita untuk punya seperangkat analisis kritis dengan paradigma kecurigaan pada selubung kepentingan yang bermain di dalam ideologi yang dipakai dan menyembunyikan kepentingan yang menyebabkan ketidakadilan. Tanpa pertama-tama mengedepankan sikap "kecurigaan hermeneutis" (hermeneutic of suspicion), menurut saya, kita sulit menemukan perspektif pengharapan tentang hidup yang lebih baik dan adil di masa depan. Pendekatan apresiatif atas kehidupan yang lebih baik merupakan hasil dari daya kritis terhadap kekuatan-kekuatan anti kehidupan yang hadir dalam aneka wajah. Jalan ini, menurut saya, merupakan isi dari metodologi atau paradigma berteologi yang diinspirasi oleh hermeneutik Ricoeur untuk membaca konteks masa kini.

\section{PENUTUP: SEBUAH PENDEKATAN TEOLOGIS DIALEKTIS}

Pertanyaan yang penting diajukan adalah apakah paradigma afirmatif-kritis dan kritis-afirmatif selalu ada dalam ketegangan yang tak terjembatani? Bisakah keduanya berfungsi dialektis? Dalam membaca realitas, tugas kritis dan afirmatif atau afirmatif dan kritis sesungguhnya bekerja secara dialektis. ${ }^{56}$ Sikap kritis-konfrontatif tidak selamanya dan satu-satunya menjadi pilihan sikap dalam memahami konteks. Sikap ini juga tidak dapat bekerja terus-menerus karena tidak ada orang yang dapat tahan dengan kritik dan perlawanan yang bertubitubi. Sikap kritis perlu dibarengi dengan tugas afirmatif terhadap konteks. Caranya dengan memberi apresiasi terhadap kehidupan yang ada pada konteks sebagai sesuatu yang darinya kita dapat belajar. Sikap yang terbuka adalah bahwa yang lain mempunyai kebenaran dan darinya dapat diperoleh nilai yang dipelajari. Inilah sikap apresiatif atas konteks yang dihadapi.

Dalam pengalaman orang Indonesia memahami realitas, sikap yang pertamatama dikedepankan adalah konfrontatif. Konteks dan seluruh isi yang hidup di dalamnya ditanggapi dengan sikap konfrontatif dan mencari perbedaan. Salah satu cara konfrontatif itu adalah explaining away terhadap konteks kemajemukan agama dan budaya, dengan menjelaskannya untuk maksud membabat habis dan menempatkan agama dan budaya sendiri di atas semua yang lain. Sikap konfrontatif sering kali tidak jauh dari sikap superioritas atas yang lain dengan membangun ketertutupan dan seperangkat klaim kebenaran atas yang lain. Karena itu sangat bisa dimengerti jika Gerrit Singgih, ${ }^{57}$ misalnya, kemudian menyarankan agar orang-orang Kristen di Indonesia yang selama ini diajari oleh kaum misionaris kolonial mengkonfrontasi realitas dan menganggapnya sebagai berasal dari setan, mau mengubah pendekatannya dengan mengedepankan sikap apresiatif dan konfirmatif. 
Seperti sudah dicatat di atas bahwa sikap konfrontatif seringkali dimaknai sempit sebagai menghakimi bahkan menolak unsurunsur baik yang ada dalam realitas. Sikap menilai sebetulnya merupakan salah satu sikap hermeneutis, ${ }^{58}$ namun menjadi masalah ketika jatuh dalam sikap menghakimi dalam klaim kebenaran yang tertutup. Yang paling mudah adalah terhadap konteks kemajemukan agama dan budaya. Agama-agama dan budaya-budaya lain dianggap sesat, berasal dari setan dan diperlakukan sebagai musuh yang layak diperangi. Yang sering dilupakan adalah sikap positif dari pendekatan konfrontatif, yaitu kritis, yang bermaksud membarui, mentransformasi dan menambahkan yang tidak ada di dalam yang sudah ada. Manfaat kacamata kritis terhadap konteks adalah menolong kita keluar dari perangkap ideologis yang seringkali sarat dominasi dan praktek kekerasan. Kesadaran akan fakta ideologis yang membelenggu ini akan memberi daya yang besar bagi gerakan-gerakan emansipasi yang diperjuangkan. Sementara itu sikap yang lain, yaitu afirmatif. Sikap ini sejajar dengan sikap konfirmatif, yang merupakan usaha membenarkan dan mengiakan segala sesuatu yang baik dan benar dalam kebudayaan-kebudayaan atau agama-agama lain. Terhadap yang lain yang berbeda kita pun dapat memperoleh wawasan (insight) untuk dipelajari bagi transformasi subjektivitas. Kedua sikap metodis ini, kritis dan afirmatif, sesungguhnya bukan sikap yang terpisah diametral satu

\section{CATATAN AKHIR}

1 Paul Ricoeur, Figuring The Sacred: Religion, Narrative, and Imagination, trans. David Pellauer and ed. Mark I. Wallace, (Minneapolis: Fortress Press, 1995), 39-41.

2 Paul Ricoeur, Figuring The Sacred: Religion, Narrative, and Imagination, 217-221.

3 Paul Ricoeur, Fallible Man, trans. Charles A. Kelbley, rev. ed., (New York: Fordham University Press, 1986), 133.

4 Dan R. Stiver, Theology after Ricoeur: New Directions in Hermeneutical Theology, (Louisville: Westminster John Knox Press, 2001), 5-10.

5 F. Budi Hardiman, Seni Memahami: Hermeneutik dari Schleiermacher sampai Derrida, (Yogyakarta: Kanisius, 2015). berhadapan dengan yang lain. Keduanya secara dialektis berjalan bersama sebagai alat atau sarana membaca realitas. Mana yang didahulukan tergantung tantangan konteks yang dihadapi. Menurut saya, konteks hari ini yang ditandai oleh roh homo oeconomicus melalui sistem globalisasi ekonomi yang tidak adil, membutuhkan metodologi berteologi untuk membaca konteks dengan mendahulukan pendekatan kritis.

Dengan menelusuri pemikiran hermeneutik Paul Ricoeur didapati kerangka metodologi berteologi untuk membaca konteks, yaitu kritis-afirmatif dan afirmatifkritis, yang keduanya secara dialektis berjalan bersama-sama. Realitas tidak hanya dikritisi, melainkan juga diafirmasi, sebaliknya, realitas tidak hanya diafirmasi, melainkan juga dikritisi. Ketegangan dialektis ini sebaiknya dipertahankan untuk menyasar tujuan ganda teologi hermeneutik, yakni meruntuhkan ilusi subjek yang absolut dan mengungkap sebuah pengharapan tentang hidup bersama secara baik dan adil. Yang pertama bermakna emansipasi ruang privat, dan yang kedua bermakna emansipasi ruang publik.

\section{John C. Simon,}

Lulusan Program Doctor of Theology Fakultas Teologi, UKDW, Yogyakarta. Mengajar pada Sekolah Tinggi Teologi Indonesia Timur (STT Intim) Makassar, Jl. Baji Dakka 7, Makassar. E-mail: tajaksebakal@gmail.com.
6 Paul Ricoeur, Oneself as Another, trans. Kathleen Blamey, (Chicago and London: The University of Chicago Press, 1992), 306.

7 Paul Ricoeur, Lectures on Ideology and Utopia, ed. George H. Taylor, (New York: Columbia University Press, 1986), 237.

8 Paul Ricoeur, Oneself as Another, 297. Paul Ricoeur, The Conflict of Interpretations: Essays in Hermeneutics, ed. Don Ihde, (Evanston: Northwestern University Press, 1974), 266.

9 Paul Ricoeur, From Text to Action: Essays in Hermeneutics, II, trans. Kathleen Blamey and John B. Thompson, (Evanston, Illinois: Northwestern University Press, 1991), 61-62. 
10 Paul Ricoeur, Hermeneutics and the Human Sciences: Essays on Language, Action and Interpretation, 158.

11 Paul Ricoeur, Lectures on Ideology and Utopia, x.

12 Boyd Blundell, Paul Ricoeur between Theology and Philosophy: Detour and Return, (Bloomington and Indianapolis: Indiana University Press, 2010), 8.

13 Paul Ricoeur, The Conflict of Interpretations: Essays in Hermeneutics, 244.

14 Ricoeur menggunakan istilah ini pertama kali (A term Ricoeur first uses in) di dalam bukunya, Paul Ricoeur, The Symbolism of Evil, trans. Emerson Buchanan, (Boston: Beacon Press, 1969), 351. Gagasan Ricoeur ini diinspirasi oleh pemikiran Karl Barth. Lihat Paul Ricoeur, A Ricoeur Reader: Reflection and Imagination, ed. Mario J. Valdes, (Toronto dan Buffalo: University of Toronto Press, 1991), 473.

15 Paul Ricoeur, The Conflict of Interpretations: Essays in Hermeneutics, 100.

16 David M. Kaplan, Ricoeur's Critical Theory, (New York: State University of New York Press, 2003), 154.

17 Paul Ricoeur, From Text to Action: Essays in Hermeneutics, II, 61.

18 Paul Ricoeur, The Conflict of Interpretations: Essays in Hermeneutics, 20.

19 Paul Ricoeur, Freud and Philosophy: An Essay on Interpretation, trans. Denis Savage, (New Haven: Yale University Press, 1970), 28, 496.

20 Paul Ricoeur, Hermeneutics and the Human Sciences: Essays on Language, Action and Interpretation, 96-97.

21 Paul Ricoeur, Hermeneutics and the Human Sciences: Essays on Language, Action and Interpretation, 79-87.

22 F. Budi Hardiman, "Kritik atas Patologi Modernitas dan [Post]Modernitas: Habermas dan Para Ahli Waris Nietzsche", Driyarkara, Th. XIX, No. 2, (1992/1993):42-61 (46, c.k. 5). Tentang reifikasi lihat Paul Ricoeur, Hermeneutics and the Human Sciences: Essays on Language, Action and Interpretation, 96-97. Paul Ricoeur, Lectures on Ideology and Utopia, 235.

23 David M. Kaplan, Ricoeur's Critical Theory, 38.

24 Paul Ricoeur, Hermeneutics and the Human Sciences: Essays on Language, Action and Interpretation, 88. Paul Ricoeur, From Text to Action: Essays in Hermeneutics, II, 295.

25 Paul Ricoeur, Hermeneutics and the Human Sciences: Essays on Language, Action and Interpretation, 91-95. Paul Ricoeur, From Text to Action: Essays in Hermeneutics, II, 298-301.

26 Paul Ricoeur, Husserl: An Analysis of His Phenomenology, trans. Edward G. Ballard and Lester E. Embree, (Evanston: Northwestern University Press, 1967), 91-92.

27 Paul Ricoeur, Oneself as Another, 172, 180

28 Paul Ricoeur, Hermeneutics and the Human Sciences: Essays on Language, Action and Interpretation, 16. Paul Ricoeur, From Text to Action: Essays in Hermeneutics, II, 138. Loretta Dornisch, "Ricoeur's Theory of Mimesis: Implications for Literature and Theology", Literature \& Theology, Vol. 3, No. 3, (November 1989):308-318.
29 Teks Inggris: "introduces me to imaginative variations of the ego". Lihat Paul Ricoeur, Hermeneutics and the Human Sciences: Essays on Language, Action and Interpretation, 94.

30 Paul Ricoeur, Time and Narrative. Vol. 3, trans. Kathleen Blamey and David Pellauer, (Chicago dan London: The University of Chicago Press, 1988), 227.

31 David M. Kaplan, Ricoeur's Critical Theory, 41.

32 Paul Ricoeur, From Text to Action: Essays in Hermeneutics, II, 294.

33 Paul Ricoeur, Hermeneutics and the Human Sciences: Essays on Language, Action and Interpretation, 87.

34 Paul Ricoeur, Hermeneutics and the Human Sciences: Essays on Language, Action and Interpretation, 33-34, 87. Paul Ricoeur, From Text to Action: Essays in Hermeneutics, II, 294

35 Kata Ricoeur: "Gadamer inevitably turned hermeneutic philosophy towards the rehabilitation of prejudice". Lihat Paul Ricoeur, Hermeneutics and the Human Sciences: Essays on Language, Action and Interpretation, 66-67, 76. Paul Ricoeur, From Text to Action: Essays in Hermeneutics, II, 273-274, 283.

36 Paul Ricoeur, Time and Narrative, Vol. 3, 227.

37 Paul Ricoeur, Time and Narrative, Vol. 3, 225.

38 Paul Ricoeur, From Text to Action: Essays in Hermeneutics, II, 79, 302. Paul Ricoeur, Hermeneutics and the Human Sciences: Essays on Language, Action and Interpretation, 95.

39 Paul Ricoeur, Oneself as Another, 432. Paul Ricoeur, The Conflict of Interpretations: Essays in Hermeneutics, 108-120 (119-120), 260, 324.

40 Paul Ricoeur, Oneself as Another, 186.

41 Paul Ricoeur, Hermeneutics and the Human Sciences: Essays on Language, Action and Interpretation, 100.

42 Paul Ricoeur, Hermeneutics and the Human Sciences: Essays on Language, Action and Interpretation, 74, 97. Paul Ricoeur, From Text to Action: Essays in Hermeneutics, II, 281, 303.

43 David M. Kaplan, Ricoeur's Critical Theory, 44.

44 Paul Ricoeur, Lectures on Ideology and Utopia, 314.

45 Paul Ricoeur, From Text to Action: Essays in Hermeneutics, II, 318.

46 Paul Ricoeur, Lectures on Ideology and Utopia, 258.

47 John C. Simon, "Hermeneutik Paul Ricoeur dan Tugas Emansipasi", Doctoral dissertation of Theology, (Yogyakarta: Universitas Kristen Duta Wacana, 2016).

48 John C. Simon, "Hermeneutik Paul Ricoeur dan Tugas Emansipasi".

49 Ricoeur, Figuring the Sacred: Religion, Narrative and Imagination, 1995, 44. Ricoeur, From Text to Action: Essays in Hermeneutics, II, 1991, 95-98 (96)

50 Paul Ricoeur, Hermeneutics and the Human Sciences: Essays on Language, Action and Interpretation, 97

51 Paul Ricoeur, Freedom and Nature: The Voluntary and the Involuntary, trans. Erazim V. Kohak, 
(Evanston Illinois: Northwestern University Press, 1966), 116.

52 Paul Ricoeur, Freedom and Nature: The Voluntary and the Involuntary, 119.

53 Paul Ricoeur, Freedom and Nature: The Voluntary and the Involuntary, 121.

54 Paul Ricoeur, Hermeneutics and the Human Sciences: Essays on Language, Action and Interpretation, 99. Paul Ricoeur, From Text to Action: Essays in Hermeneutics, II, 305. Paul Ricoeur, Oneself as Another, 172, 180, 239.

55 Sebetulnya Ricoeur sendiri sudah menyadari urutan distortif dan integratif ini ketika ia mengatakan sendiri: "two layers of ideology ideology as distortion and as the legitimation of a system of order or power- the integrative function of ideology, the function of preserving an identity, remains". Lihat Paul Ricoeur, Lectures on Ideology and Utopia, 258.

56 Paul Ricoeur, Lectures on Ideology and Utopia, 258.

57 E.G. Singgih, Iman dan Politik dalam Era Reformasi di Indonesia, (Jakarta: BPK Gunung Mulia, 2004), 176. E.G. Singgih, Berteologi dalam Konteks: Pemikiran-pemikiran Mengenai Kontekstualisasi Teologi di Indonesia, (Jakarta dan Yogyakarta: BPK Gunung Mulia dan Kanisius, 2004), 171.

58 Paul Ricoeur, Hermeneutics and the Human Sciences: Essays on Language, Action and Interpretation, 279.

\section{DAFTAR RUJUKAN}

Blundell, Boyd. Paul Ricoeur between Theology and Philosophy: Detour and Return. Bloomington and Indianapolis: Indiana University Press, 2010.

Dornisch, Loretta. "Ricoeur's Theory of Mimesis: Implications for Literature and Theology". Literature \& Theology . Vol. 3, No. 3, (November 1989).

Hardiman, F. Budi. Seni Memahami: Hermeneutik dari Schleiermacher sampai Derrida. Yogyakarta: Kanisius, 2015.

. "Kritik atas Patologi Modernitas dan [Post]Modernitas: Habermas dan Para Ahli Waris Nietzsche". Driyarkara, Th. XIX, No. 2, (1992/1993).

Kaplan, David M. Ricoeur's Critical Theory. New York: State University of New York Press, 2003.
Ricoeur, Paul. Freedom and Nature: The Voluntary and the Involuntary. Trans. Erazim V. Kohak. Evanston Illinois: Northwestern University Press, 1966.

Husserl: An Analysis of His Phenomenology. Trans. Edward G. Ballard and Lester E. Embree. Evanston: Northwestern University Press, 1967.

The Symbolism of Evil. Trans. Emerson Buchanan. Boston: Beacon Press, 1969.

. Freud and Philosophy: An Essay on Interpretation. Trans. Denis Savage. New Haven: Yale University Press, 1970.

The Conflict of Interpretations: Essays in Hermeneutics. Ed. Don Ihde. Evanston: Northwestern University Press, 1974.

- Hermeneutics and the Human Sciences: Essays on Language, Action and Interpretation. Ed. John B. Thompson. Cambridge: Cambridge University Press, 1982.

- Fallible Man. Trans. Charles A. Kelbley, Rev. Ed. New York: Fordham University Press, 1986.

. Lectures on Ideology and Utopia. Ed. George H. Taylor. New York: Columbia University Press, 1986.

. Time and Narrative. Vol. 3. Trans. Kathleen Blamey and David Pellauer. Chicago dan London: The University of Chicago Press, 1988.

. A Ricoeur Reader: Reflection and Imagination. Ed. Mario J. Valdes. Toronto dan Buffalo: University of Toronto Press, 1991.

. From Text to Action: Essays in Hermeneutics. II. Trans. Kathleen Blamey and John B. Thompson. Evanston, Illinois: Northwestern University Press, 1991. 
Oneself as Another. Trans. by Kathleen Blamey. Chicago and London: The University of Chicago Press, 1992.

Figuring The Sacred: Religion, Narrative, and Imagination. Trans. David Pellauer and ed. Mark I. Wallace. Minneapolis: Fortress Press, 1995.

Simon, John C. "Hermeneutik Paul Ricoeur dan Tugas Emansipasi". Doctoral dissertation of Theology. Yogyakarta: Universitas Kristen Duta Wacana, 2016.
Singgih, E.G. Berteologi dalam Konteks: Pemikiran-pemikiran Mengenai Kontekstualisasi Teologi di Indonesia. Jakarta dan Yogyakarta: BPK Gunung Mulia dan Kanisius, 2004.

- Iman dan Politik dalam Era Reformasi di Indonesia. Jakarta: BPK Gunung Mulia, 2004.

Stiver, Dan R. Theology after Ricoeur: New Directions in Hermeneutical Theology. Louisville: Westminster John Knox Press, 2001. 